\title{
Frequency of renal tubular acidosis in children with down syndrome
}

\section{Silvestre García de la Puente ${ }^{1 *}$, Karla Adney Flores Arizmendi ${ }^{2}$, Junior Rafael Gahona Villegas ${ }^{3}$, Paola Andrea Yepes Genoy ${ }^{4}$ and Elena Lissette Garza Guerrero ${ }^{4}$}

\author{
${ }^{1} \mathrm{PhD}$, Head of Department of Research Methodology, Instituto Nacional de Pediatría, Mexico \\ ${ }^{2}$ Paediatrician, Head of the Down Syndrome Clinic, Instituto Nacional de Pediatría, Mexico \\ ${ }^{3}$ Paediatric nephrologist, Instituto Nacional de Pediatría and Hospital Pediátrico Baca Ortiz, \\ Pontificia Universidad Católica del Ecuador, Hospital Metropolitano, Quito, Ecuador \\ ${ }^{4}$ Paediatrician, Instituto Nacional de Pediatría, Mexico
}

\section{Abstract}

Background: Down syndrome (DS) is associated with various congenital diseases and malformations, including those of the kidneys and urinary tract. It has been thought that renal tubular acidosis (RTA) is more frequent in this population. The objective of this study was to assess the frequency of RTA and, secondarily, of other renal and urological disorders in persons with DS.

Method: An observational, ambispective, descriptive and cross-sectional study of patients diagnosed with RTA, or suspected kidney or urological disorders, was carried out from July 2016 to September 2017 at the Down syndrome clinic of the Mexican National Institute of Paediatrics. Urinalysis was performed, along with analyses of venous blood gas, sodium, potassium, chlorine, calcium, phosphorus, albumin and creatinine. Those with any abnormal values were referred to nephrology for diagnostic evaluation.

Results: Of a total of 700 patients seen at the clinic, 47 met the selection criteria. Of these, 32 had no RTA or other renal or urological alterations. The remaining 15 continued to the second phase of the study, where 6 were diagnosed with nephropathy or uropathy (RTA, systemic arterial hypertension, monosymptomatic familial haematuria, mild renal failure secondary to reflux nephropathy, urinary tract infection or right ureteropelvic stenosis). Four had mild metabolic acidosis without meeting the criteria for diagnosis of RTA.

Conclusion: RTA is not more common in children with Down syndrome. Nephropathies and uropathies should be investigated in the evaluation of DS patients.

\section{More Information}

*Address for Correspondence:

Silvestre García de la Puente, PhD, Head of Department of Research Methodology, Instituto Nacional de Pediatría, Mexico,

Email: garciadelapuente@hotmail.com

Submitted: 15 September 2020

Approved: 01 October 2020

Published: 02 October 2020

How to cite this article: de la Puente SG, Arizmendi KAF, Villegas RG,jr, Genoy PAY Guerrero ELG. Frequency of renal tubular acidosis in children with down syndrome. J Clini Nephrol. 2020; 4: 061-064.

DOI: 10.29328/journal.jcn.1001060

Copyright: () 2020 de la Puente SG, et al This is an open access article distributed under the Creative Commons Attribution License, which permits unrestricted use, distribution, and reproduction in any medium, provided the original work is properly cited.

Keywords: Renal tubular acidosis; Down syndrome; Growth arrest; Children

Check for updates

OPEN ACCESS

\section{Background}

Down syndrome (DS) is the most common chromosomopathy in humans, with a frequency of 1 in 700 live new-borns [1]. The clinical manifestations are highly variable and have well-established frequencies. The most prevalent and distinctive alterations are intellectual disability and short stature [2]. Growth arrest can be associated with different congenital diseases and malformations, including heart disease and gastrointestinal, endocrinological and kidney or urinary tract problems. The latter are present in $3.2 \%$ of people with DS, as compared with $0.7 \%$ of the general population [3], and among them, tubulopathies present growth arrest as the main symptom. The growth of children with DS, from the prenatal stage through adulthood, differs markedly from that of the rest of the population [4]. It should be evaluated using weight and height charts specific to the condition.

At the Down syndrome clinic of the Mexican National Institute of Paediatrics, of approximately 700 patients with this condition seen from July 2016 to September 2017, $47(6.7 \%)$ were diagnosed with suspected renal tubular acidosis (RTA) due to growth arrest in the absence of a wellestablished organic cause. The objective of this study was to investigate the real frequency of RTA and other renal and urinary disorders in this group of children.

\section{Methods}

An observational, ambispective, descriptive and cross- 
sectional study was carried out from July 2016 to September 2017 in patients diagnosed with RTA, or suspected renal or urological disorders, at the Down syndrome clinic of the Mexican National Institute of Paediatrics, which is a Level III hospital in Mexico City. Participants were patients under 18 years of age with a previous diagnosis or suspicion of RTA or any other renal or urological alteration, according to their clinical history and laboratory or clinical studies. Patients who came to the clinic during the study period and who met the selection criteria were informed of the nature of the study, along with their parents or guardians.

Participants taking alkalizing solutions were asked to suspend doing so for a week before the laboratory studies were performed. Initial analyses included urinalysis, venous blood gas, sodium $(\mathrm{Na})$, potassium $(\mathrm{K})$, chlorine $(\mathrm{Cl})$, calcium (Ca), phosphorus (P), albumin and creatinine. Those with any abnormal values were referred for nephrology consultation. The blood gas and urinary $\mathrm{pH}$ analysis were performed with a Brinkmann Metrohm Model $632 \mathrm{pH}$ meter, and the other analyses with a Beckman Coulter DxC 700 AU chemistry analyzer. The criteria for diagnosis of renal tubular acidosis (RTA) or other uropathy or nephropathy were as follows: Probable RTA diagnosis (without other cause of metabolic acidosis): blood $\mathrm{pH} \leq 7.37$, anion gap $<18$ and bicarbonate less than $18 \mathrm{mmol} / \mathrm{L}(<2$ years of age), $19 \mathrm{mmol} / \mathrm{L}(2-5$ years) or $20 \mathrm{mmol} / \mathrm{L}$ ( $>5$ years); RTA ruled out: blood $\mathrm{pH} \geq 7.4$, irrespective of the anion gap, and bicarbonate greater than $21.5 \mathrm{mmol} / \mathrm{L}(<2$ years of age), $22 \mathrm{mmol} / \mathrm{L}$ (2-5 years) or $22.5 \mathrm{mmol} / \mathrm{L}$ ( $>5$ years); uncertain RTA diagnosis: intermediate values that neither confirm nor rule out the diagnosis; renal or urological alterations: history of urinary infections or disorders, urinalysis alterations, serum creatinine higher than expected for participant's age. These participants underwent complementary diagnostic studies.

Participants with a probable or uncertain diagnosis of tubular acidosis provided additional samples for analysis of venous blood gas, $\mathrm{Na}, \mathrm{K}, \mathrm{Cl}$, albumin and creatinine, and a 2-hour urine collection [5] was analysed for $\mathrm{pH}, \mathrm{Na}, \mathrm{K}, \mathrm{Cl}$, $\mathrm{HCO}_{3}, \mathrm{Ca}$, creatinine and citrates to confirm or rule out the RTA diagnosis and confirm the type of RTA. Appropriate studies were carried out on participants with suspected or diagnosed renal or urological disorders.

\section{Sample size}

A convenience sample was used, since the patients of the Down syndrome clinic are generally seen every 6 to 12 months for routine studies, and most of them would be seen over the course of the study period.

\section{Statistical analysis}

Descriptive statistics were used. The numerical variables are summarized with medians, minima and maxima. The categorical variables are summarized with frequencies and percentages as well as the frequency of RTA and other renal or urological alterations.

\section{Results}

In the study period, the Down syndrome clinic had a population of 700 patients, who were seen periodically, at least every 6 months. Of the total, 47 met the selection criteria (Figure 1), and of those, 32 did not have RTA or other renal or urological alteration. The remaining 15 went on to the second phase of the study, and 6 were diagnosed with nephropathy or uropathy (Table 1). The patient with tubular acidosis was a two-year-old girl with blood $\mathrm{pH} 7.28, \mathrm{HCO}_{3}$ $16.3 \mathrm{mmol} / \mathrm{L}, \mathrm{pCO}_{2} 35.1 \mathrm{mmHg}, \mathrm{K} 4.6 \mathrm{mmol} / \mathrm{L}$, creatinine $0.5 \mathrm{mmol} / \mathrm{L}$, a plasmatic anion gap of $14 \mathrm{mmolL}$, urine $\mathrm{pH}$ 6, urinary anion gap $38 \mathrm{mmol} / \mathrm{L}$, fractional excretion of bicarbonate $1.8 \%, \mathrm{Ca} / \mathrm{Cr}$ ratio 0.04 , renal ultrasound with right renal hypoplasia. Ammonia was not analyzed and no special tests were performed for precise diagnosis of tubular acidosis. The participant with systemic arterial hypertension was provided with advice on changes in lifestyle (diet and exercise), and the rest of the participants continued to be monitored. Demographic data with growth percentiles and laboratory results are summarized in table 1 . Of the 47 patients studied, 4 had mild metabolic acidosis, without meeting the criteria for the diagnosis of RTA according to the criteria described in the Methods section; on subsequent visits it was found to have disappeared (Table 2).



Figure 1: Flowchart of study procedure.

\begin{tabular}{|c|c|c|c|}
\hline \multicolumn{4}{|c|}{ Table 1: Clinical and laboratory data in 47 patients. } \\
\hline Numerical variable & Median & Minimum & Maximum \\
\hline Age & 4 years & 3 months & 14 years \\
\hline $\mathrm{pH}$ & 7.35 & 7.28 & 7.51 \\
\hline $\mathrm{HCO}_{3}(\mathrm{mmol} / \mathrm{L})$ & 23 & 16.3 & 31.9 \\
\hline $\mathrm{pCO}_{2}(\mathrm{mmHg})$ & 42.1 & 22.4 & 53.1 \\
\hline $\mathrm{Na}(\mathrm{mmol} / \mathrm{L})$ & 138 & 129 & 144 \\
\hline $\mathrm{K}(\mathrm{mmol} / \mathrm{L})$ & 4.4 & 3.2 & 5.6 \\
\hline $\mathrm{Cl}(\mathrm{mmol} / \mathrm{L})$ & 106 & 91 & 112 \\
\hline $\mathrm{Ca}(\mathrm{mg} / \mathrm{dL})$ & 9.4 & 8.1 & 10.3 \\
\hline $\mathrm{P}(\mathrm{mg} / \mathrm{dL})$ & 5.3 & 3.4 & 6.3 \\
\hline Creatinine $(\mathrm{mg} / \mathrm{dL})$ & 0.36 & 0.19 & 0.7 \\
\hline Albumin $(\mathrm{g} / \mathrm{dL})$ & 4 & 3.2 & 5 \\
\hline
\end{tabular}




\begin{tabular}{|c|c|c|}
\hline Categorical variable & Frequency & Percentage \\
\hline Gender & 25 & 53.2 \\
\hline Male & 22 & 46.8 \\
\hline Female & 14 & 29.8 \\
\hline Height percentile & 11 & 23.4 \\
\hline$<5$ & 22 & 46.8 \\
\hline $5-10$ & 21 & 44.7 \\
\hline$>10$ & 19 & 40.4 \\
\hline Weight percentile & 7 & 14.9 \\
\hline$<5$ & 1 & 2.1 \\
\hline $5-10$ & 1 & 2.1 \\
\hline$>10$ & 1 & 2.1 \\
\hline Conditions found & 1 & 2.1 \\
\hline Renal tubular acidosis & 1 & 2.1 \\
\hline Familial haematuria & & 2.1 \\
\hline $\begin{array}{c}\text { Mild renal failure } \\
\text { secondary to reflux } \\
\text { nephropathy }\end{array}$ & & \\
\hline Urinary infection & 1 & \\
\hline $\begin{array}{c}\text { Right ureteropelvic } \\
\text { stenosis }\end{array}$ & 1 & \\
\hline $\begin{array}{c}\text { Systemic arterial } \\
\text { hypertension }\end{array}$ & & \\
\hline
\end{tabular}

Table 2: Patients with metabolic acidosis without renal tubular acidosis.

\begin{tabular}{|c|c|c|c|}
\hline Age (years) & $\mathbf{p H}$ & $\mathrm{HCO}_{3}(\mathbf{m m o l} / \mathbf{L})$ & $\mathbf{p C O}_{2}(\mathbf{m m H g})$ \\
\hline 1 & 7.36 & 18.4 & 33.9 \\
\hline 1 & 7.39 & 20 & 34.1 \\
\hline 2 & 7.34 & 19.2 & 36.9 \\
\hline 1 & 7.37 & 18.4 & 32.6 \\
\hline
\end{tabular}

\section{Discussion}

In children with growth arrest in whom the major comorbidities have been ruled out, a renal cause such as urinary infection, glomerulopathy, kidney failure or tubulopathy should be considered. Among these, RTA [6] stands out for its frequency. There are no studies of the frequency of RTA in patients with Down syndrome; however, we believe there is, as in the rest of the paediatric population, an overdiagnosis. The estimated $6.7 \%$ of patients with this diagnosis in the Down syndrome clinic were evaluated and treated by different services within the hospital without the necessary laboratory studies. A thorough analysis confirmed the diagnosis in a single patient $(0.14 \%)$, and it was secondary to renal hypoplasia. Other abnormalities of the urinary and renal tracts were also found. There are no exact figures on the frequency of RTA in the general population. Garcia De La Puente, et al. [7] found 35 cases for every 10,000 patient charts at the National Institute of Paediatrics. The incidence and prevalence of RTA secondary to urological disorders are not clear; these are not described in many studies. A study by Guizar carried out in Mexico [8] reported the presence of RTA in patients with vesicoureteral reflux (VUR), with 9 of the 18 patients with VUR presenting RTA. However, this study did not relate the degree of VUR to the onset of RTA or mention the time of RTA onset. According to Kupferman [3], the prevalence of renal and urinary tract malformations in people with Down syndrome was 3.2\%, as compared with $0.7 \%$ in those without DS. The probability of urine acidification defects would depend on the degree or severity of the malformation, as well as the duration of the alteration before its correction. There are no studies in the literature of any genetic relationship between RTA and DS.

Other studies demonstrate the greater frequency of alterations in the urological and renal tracts in people with DS [9-12]: these are the third most common defect, after cardiac and gastrointestinal abnormalities, in persons with this syndrome. Autopsy studies have described a range of renal disorders, mainly renal hypoplasia, and cystic diseases including glomerular microcysts [13]. In an examination of glomerular lesions in DS, Lo, et al. [14] report two cases with focal glomerulosclerosis, and in a review of 43 autopsy studies evaluating mainly glomerular lesions, they found one case of acute glomerulonephritis, another with minimal change nephropathy and a third with membranous glomerulonephritis. They also found a high frequency of glomerular microcysts. Functionally, glomerular filtration in children with DS has been reported to be approximately $80 \%$ of that in those without DS, according to Yamakawa, et al. [15]; these authors suggest that the difference could be the result of smaller kidneys or fewer glomeruli. In the present study, the method of data collection underestimated the real rate of urological and renal malformations in this population, since the cases identified were among patients suspected to have RTA or other renal or urological alterations, not among the entire patient population at the Down syndrome clinic or among those who had already been diagnosed with a malformation.

Given the higher frequency of renal and urological disorders in patients with DS, we recommend that medical providers ask about urinary symptoms and perform physical examinations including blood pressure measurement at least annually, along with analyses of blood chemistry with electrolytes, blood biometry and a general urine test. We also recommend a kidney and urinary tract ultrasound at least once. These tests all help to detect early comorbidities. In the absence of malformations that affect growth, we believe that specific tests for RTA should be carried out only if a patient's weight or height are below the 5th percentile for children with DS. In sum, RTA is not more frequent in children with DS, but they should be examined routinely for the presence of renal or urinary tract disorders.

\section{Compliance with ethical standards}

This work was carried out in accordance with the principles of the Declaration of Helsinki. It was approved by the Research and Research Ethics Boards of the Instituto Nacional de Pediatría, Mexico City, Mexico (US DHHS OHRP nos. IRB00008064 and IRB00008065; approval no. $2016 / 040$ ). A copy of the approval is available upon request. Informed assent (where possible) and the written informed consent of patients' parents or guardians was obtained. 


\section{Financing}

This work received financial support from the Instituto Nacional de Pediatría, Mexico City (Project No. 2016/040).

\section{References}

1. Parker SE, Mai CT, Canfield MA, Rickard R, Wang Y, et al. Updated national birth prevalence estimates for selected birth defects in the United States, 2004-2006. Birth Defects Res Part A - Clin Mol Teratol. 2010; 88: 1008-1016.

PubMed: https://pubmed.ncbi.nlm.nih.gov/20878909/

2. Asim A, Kumar A, Muthuswamy S, Jain S, Agarwal S. Down syndrome: an insight of the disease. J Biomed Sci. 2015; 22: 41. http://www.jbiomedsci.com/content/22/1/41

3. Kupferman JC, Druschel CM, Kupchik GS. Increased prevalence of renal and urinary tract anomalies in children with Down syndrome. Pediatrics. 2009;124: e615-621.

PubMed: https://pubmed.ncbi.nlm.nih.gov/19752083/

4. Fitz Simmons J, Droste S, Shepard TH, Pascoe-Mason J, Chinn A, et al. Long-bone growth in fetuses with Down syndrome. Am J Obstet Gynecol. 1989; 161: 1174-1477.

PubMed: https://pubmed.ncbi.nlm.nih.gov/2531547/

5. Rocha-Gómez MI, Zaltzman-Girshëvich S, García-De La Puente S. Utilidad de la recolección de orina de dos horas para el diagnóstico del tipo de acidosis tubular renal. Acta Pediatr Mex. 2015; 36: 322-329.

6. Alexander RT, Bitzan M. Pediatr Clin North Am. 2019; 66: 135-157.

7. García de la Puente S. Acidosis tubular renal. Acta Pediatr. 2006; 27: 268-278. www.revistasmedicas.com.mx
8. Guizar JM, Kornhauser C, Malacara JM, Sanchez G, Zamora J. Renal tubular acidosis in children with vesicoureteral reflux. J Urol. 2019; 156: 193-195.

PubMed: http://www.ncbi.nlm.nih.gov/pubmed/8648800

9. Kupferman JC, Stewart CL, Kaskel FJ, Fine RN. Posterior urethral valves in patients with Down syndrome. Pediatr Nephrol. 1996; 10: 143-146.

PubMed: https://pubmed.ncbi.nlm.nih.gov/8703697/

10. Jain M, Singh A, Mantan M, Kapoor S. Evaluation of structural anomalies of kidney and urinary tract in children with down syndrome. Indian J Pediatr. 2014; 81: 73.

11. Málaga S, Pardo R, Málaga I, Orejas G, Fernández-Toral J. Renal involvement in Down syndrome. Pediatr Nephrol. 2005; 20: 614-617. PubMed: https://pubmed.ncbi.nlm.nih.gov/15785939/

12. Mercer ES, Broecker B, Smith EA, Kirsch AJ, Scherz HC, et al. Urological manifestations of Down syndrome. Vol. 171, Journal of Urology. Lippincott Williams and Wilkins; 2004: 1250-1253. PubMed: https://pubmed.ncbi.nIm.nih.gov/14767322/

13. Ariel I, Wells TR, Landing BH, Singer DB. The urinary system in down syndrome: A study of 124 autopsy cases. Fetal Pediatr Pathol. 1991; 11: 879-888.

PubMed: https://pubmed.ncbi.nlm.nih.gov/1837925/

14. Lo A, Brown HG, Fivush BA, Neu AM, Racusen LC. Renal disease in Down syndrome: Autopsy study with emphasis on glomerular lesions. Am J Kidney Dis. 1998; 31: 329-335. PubMed: https://pubmed.ncbi.nlm.nih.gov/9469506/

15. Yamakawa S, Nagai T, Uemura O. Down syndrome and mild kidney dysfunction. Pediatr Int. 2019; 60: 391-393. 